DOI: $10.4274 /$ tjps.20981

\title{
Decreased Protein Kinase C expressions in the cochlear fibroblasts of diabetic rat models induced by curcumin
}

Tengku Siti Hajar Haryuna, Farhat Farhat, Siska Indriany

Department of Otorhinolaryngology-Head and Neck Surgery, Faculty of Medicine, Universitas Sumatera Utara, Medan 20155, Indonesia

\begin{abstract}
INTRODUCTION: Microcirculation and hemodynamic disturbances, including in the cochlea, are commonly found in diabetic patients. A study on diabetic rats discovered the histopathological changes in outer hair cells, spiral ganglion and mitochondrial damage in the ear. Hyperglycemia can increase the activation of Protein Kinase $C$ (PKC). Curcumin as an antioxidant also affects the regulation of PKC and $\mathrm{Ca} 2+$. The aim of this study is to learn the role of curcumin in decreasing the PKC expressions in the cochlear fibroblasts of diabetic rats.

METHODS: An experimental study on 24 Wistar rats divided into 6 groups. Group 1: control group; group 2: diabetic group without curcumin administration; group 3 and 4: diabetic groups with curcumin administration $(200 \mathrm{mg} / \mathrm{kgbw}$ and $400 \mathrm{mg} / \mathrm{kgbw}$ for 3 days, respectively); group 5 and 6: diabetic groups with curcumin administration (200 mg/kgbw and $400 \mathrm{mg} / \mathrm{kgbw}$ for 8 days, respectively). Cochlear tissues were taken from all groups and immunohistochemistry-stained, and the PKC expression scores were analysed with One-Way ANOVA (a significance level of 0.05 ).

RESULTS: Significant differences in PKC expressions $(p<0.05)$ were found between group 1 and group 2, group 2 and group 3, 4, 5, 6. There was no significant difference in PKC expression regarding the different doses and the duration of curcumin administration.
\end{abstract}

DISCUSSION AND CONCLUSION: Curcumin can reduce the PKC expressions in the cochlear fibroblasts of diabetic rats.

Keywords: Diabetes mellitus, curcumin, fibroblast, cochlea, protein kinase $\mathrm{C}$ 


\section{Introduction}

Diabetes Mellitus (DM) is a chronic disease caused by the inadequate production of insulin or ineffective usage of the provided insulin, marked by the increase in blood glucose (hyperglycemia), and found as an inherited disease. It is estimated that, there will be 300 million diabetic patients worldwide in 2025.

Diabetes has the potential to cause various complications due to angiopathy and neuropathy. It has long been studied about the relationship between DM and hearing loss. Disturbances in microcirculation and hemodynamic changes (including in cochlea) are often found in diabetic patients. Further study on experimental animals such as diabetic rats has reported the pathological changes in outer hair cell, spiral ganglion and mitochondrial damage. $^{2}$

The similar result can also be found in a study conducted by Lee, et $\mathrm{al}^{3}$, which found histologic abnormalities, such as degeneration of organ of Corti and spiral ganglion cells, related to hyperglycemia and obesity.

Several biochemical pathways have also been studied to discover the effect of hyperglycemia, such as diacylglycerol (DAG) activation pathway, protein kinase C (PKC) activation, increased polyol, increased oxidative stress and overproduction of advanced glycation end products (AGEP). These biochemical pathways are strongly related to the reactive oxygen species (ROS) leading to vascular damage..$^{4,5}$

Some existing hypotheses explain the harmful side effects of hyperglycemia, one of them is the constant activation of PKC. PKC has been linked to vascular changes, such as increased permeability, contractility, extracellular matrix synthesis, cell growth and apoptosis, angiogenesis, cytokines activity and inhibition. ${ }^{6}$

Curcumin is an active, yellow-colored component of turmeric, isolated from Curcuma longa plant. This molecule has a therapeutic effect on various diseases especially anti-inflammatory, anti-microbial, and antioxidant. It has been reported that curcumin is a bifunctional antioxidant possessing direct and indirect antioxidant activity by scavenging ROS and neutralizing them and inducting upregulation of various cytoprotective proteins and antioxidants such superoxide 
dismutase (SOD), catalase (CAT) and glutathione peroxidase (GPx). The presence of phenolic $\mathrm{OH}$ and $\mathrm{CH}_{2}$ groups in $\beta$-diketon part of this natural compound significantly contribute to its potent antioxidant property. $7,8,9$

Curcumin affects the PKC and $\mathrm{Ca}^{2+}$ regulation. The effect of inhibited ROS caused by curcumin depends on the curcumin dose through its effect on PKC activity and $\mathrm{Ca}^{2+}$ regulation. ${ }^{10}$

The role of curcumin in the treatment and prevention of hearing loss through its inhibitory mechanism towards PKC in cochlear fibroblasts of diabetic rat (Rattus novergicus) has never been studied, so the objective of this study is to demonstrate the role of curcumin in reducing the PKC expressions in the cochlear fibroblasts of diabetic rat (Rattus novergicus).

\section{Materials and Methods}

\section{Animal Subjects}

This study was an experimental study with randomized posttest-only control group design subjected to Wistar rats (Rattus norvegicus), male, healthy, average weight of $200 \mathrm{mg}$.

Twenty-four rats were divided into 6 groups, with 4 rats in each group. These rats were obtained from Laboratory of Biochemistry, Faculty of Medicine, Universitas Airlangga, Surabaya, Indonesia.

To ensure that all the procedures are ethically feasible, a proposal has been submitted to Research Ethics Committee. This study has earned the approval from Health Research Ethics Committee of Universitas Sumatera Utara Indonesia no. 433/KOMET/FKUSU/2015.

\section{Treatments}

In the study, after the white rats adapted to the cage environment at the laboratory for two weeks, they were treated according to the plan.

Group 1 (control group) was injected with single dose of sodium citrate, obtained from 1.47 gram sodium citrate solution in $50 \mathrm{~mL}$ dH2O intraperitoneally on the 1st day, and then terminated on the 5th day.

Group 2 was injected with single dose of streptozotocin/STZ (Bioworld, US) 60 $\mathrm{mg} / \mathrm{kgbw}$, and then terminated on the 5th day. 
Group 3 was injected with single dose of STZ $60 \mathrm{mg} / \mathrm{kgbw}$ followed by curcumin $200 \mathrm{mg} / \mathrm{kgbw} /$ day orally for 3 days and terminated on the 5th day.

Group 4 was injected with single dose of STZ $60 \mathrm{mg} / \mathrm{kgbw}$ followed by curcumin $400 \mathrm{mg} / \mathrm{kgbw} /$ day orally for 3 days and terminated on the 5th day.

Group 5 was injected with single dose of STZ $60 \mathrm{mg} / \mathrm{kkgbw}$ followed by curcumin $200 \mathrm{mg} / \mathrm{kgbw} /$ day orally for 8 days and terminated on the 10th day.

Group 6 was injected with single dose of STZ $60 \mathrm{mg} / \mathrm{kgbw}$ followed by curcumin $400 \mathrm{mg} / \mathrm{kgbw} /$ day orally for 8 days and terminated on the 10th day.

\section{Procedures}

a) Streptozotocin-induced diabetes

Rats fasted for 4 hours to empty the stomach and decrease the risk of aspiration. Induction was performed on rats by injecting STZ solution 60 $\mathrm{mg} / \mathrm{kgbw}^{11}$ intraperitoneally with the required doses mentioned above (diabetic groups: group 2, 3, 4, 5 and 6). In order to avoid post-injection sudden hypoglycemic, the rats were given sucrose $10 \%$ or dextrose $10 \%$ solution throughout the 1 st night. Every morning, the fasting blood sugar level of the rats were examined with Advance Glucometer (Boehringer Mannheim, German) by taking the blood from the peripheral blood vessel on the tail. Hyperglycemic is diagnosed when the blood sugar level is $>200 \mathrm{mg} / \mathrm{dl}$ after 48 hours of the STZ induction. ${ }^{12}$ If the blood sugar is $<200 \mathrm{mg} / \mathrm{dl}$ then rats are eliminated from the sample.

After being diagnosed as hyperglycemic, the rats were given curcumin according to the required dose per group and rats were terminated after the procedure.

b) Procedure of curcumin administration

In this study, powdered curcumin was used with the level (16.62 \pm 0.14)\% b/b using Thin Layer Chromatography (TLC) - Densitometry method. The given preparation included powdered curcumin with dose of $200 \mathrm{mg} / \mathrm{kgbw} / \mathrm{day}$ and $400 \mathrm{mg} / \mathrm{kgbw} / \mathrm{day}$ per rat suspended in Carboxy Methyl Cellulose (CMC) $0.5 \%$ and administered orally into the stomach of the rat via Nasogastric Tube (NGT).

c) Procedure of rat cochlear tissue collection 
Termination was conducted on rats in all groups by temporal bone necropsy. The taken tissue sample was fixated with buffered formalin solution $10 \%$ and decalcified with EDTA for 4 weeks. Each tissue sample was prepared in paraffin blocks and sliced into $4 \mu \mathrm{m}$ thick section and placed inside the glass object and then stained with Hematoxylin-Eosin and immunohistochemical staining of PKC was performed with Polyclonal Anti-PKC Antibody (catalog\#:ENT3752, Elabscience).

d) Cell-counting method

All slides were examined with Olympus XC 10 microscopes (under 40x magnification) by two anatomical pathologist separately with doubleblind method. PKC expression scores were evaluated by multiplying the area-score $(0=0 \%, 1=>10 \%, 2=10 \%-50 \%, 3=>50 \%)$ with intensity score $(0,1,2$ or 3$) .{ }^{13}$

e) Statistical analysis

To analyse the mean differences between more than two groups, OneWay ANOVA statistical test was used (a significance level of 0.05). Before One-Way ANOVA test, we did the Shapiro-Wilk test to proved that the data is normally distributed and Post Hoc Tests to see the defferences of groups.

\section{Results}

The mean differences of PKC expressions were seen in all groups. The lowest PKC expression was found in the control group and the highest PKC expression was found in diabetic group without curcumin administration (chart 1).

Chart 1: The average value of PKC expression in the cochlear lateral fibroblast wall of all groups

It was also seen in chart 1 that the diabetic groups with curcumin administration (group 3, 4, 5 and 6) had lower mean values of PKC expressions compared to the diabetic group without curcumin administration (group 2). 
In order to get a proper and detailed view of the cochlear tissue histopathologically, Hematoxylin-Eosin staining was performed and used as a comparison for further immunohistochemical staining (Figure 1).

Figure 1. The cochlear lateral wall section of Rattus Norvegicus (black arrow) with Hematoxylin-Eosin staining (under 40x magnification)

Clinical test results of curcumin in decreasing PKC expressions in the cochlear fibroblasts of diabetic rats can see in figure 2 .

Figure 2. The expressions of PKC in each group (under $100 x$ magnification): (A) Group 1; (B) Group 2; (C) Group 3; (D) Group 4; (E) Group 5; (F) Group 6. The yellow arrow indicates the expressions of PKC in cochlear fibroblasts marked by brown stains.

The fibroblasts within diabetic group (group 2) showed higher density compared to other groups. Whereas the fibroblasts within the diabetic group with curcumin administration (group 3, 4, 5 and 6) showed lower density.

The obtained results from the histopathological examination above were then processed and analysed statistically to find the differences between each group and the interpreted results were shown in table 1.

According to table 1 , there was a statistically significant difference $(p<0.05)$ in the mean value of PKC expression between group 1 and diabetic group without curcumin administration (group 2).

As shown in table 1, it was found that the administration of curcumin for diabetic groups (group 3, 4, 5 and 6) decreased the PKC expressions significantly $(p<0.05)$ compared to diabetic group without curcumin administration (group 2).

According to table 1, it was also found that the different doses (200 and $400 \mathrm{mg} / \mathrm{kgbw} / \mathrm{day}$ ) and the duration of curcumin administration (3 and 8 days) showed no statistically significant differences $(p>0.05)$ in PKC expressions. 


\section{Discussion}

Sensorineural hearing loss in diabetic patients is caused by cochlear angiopathy characterised by the dilatation of blood vessels of the stria vascularis, atrophy, and the loss of outer hair cells. A study on diabetic rats has found that microangiopathy occurs inside the inner ear and thickening of basement membranes of capillaries in stria vascularis. ${ }^{14,15}$

To help identifying the gene that play a role in human's auditory system, a rat is used as an experimental animal since it is genetically similar to a human $(>70 \%){ }^{16}$ The objective of this study is to learn the role of curcumin in decreasing the PKC expressions in the cochlear fibroblasts of diabetic rats (Rattus novergicus).

The earlier studies have not proved the curcumin effect to the PKC expression in lateral wall of cochlear fibroblasts in diabetic model rats. This study is the first study which proved that curcumin is able to decreased the expression of PKC in lateral wall of cochlear fibroblasts in diabetic model rats.

The dose of curcumin used in this study was $200 \mathrm{mg} / \mathrm{kgbw}$ according to the previous study, at which that mentioned dose of curcumin is able to act as an antioxidant ${ }^{17}$ due to its inhibitory effect on ROS by affecting the PKC pathway and calcium regulation. ${ }^{10}$ In order to find the optimal dose and duration of curcumin administration to decrease the PKC expressions, we compared the dose of $200 \mathrm{mg} / \mathrm{kgbw} /$ day and $400 \mathrm{mg} / \mathrm{kgbw} /$ day with the duration of administration for 3 and 8 days. In regards to the existing study, curcumin is a compound that functionates dependently on the dose and duration of administration. Thus, the dose and duration of administration can affect the gene expression. ${ }^{18}$

The significant difference in the mean value of PKC expression between control group and diabetic group without curcumin administration was found in this study. Curcumin as an antioxidant can inhibit ROS via PKC pathway and calcium regulation. ${ }^{10}$ This discovery strengthens the presumption that hyperglycemia will cause cellular dysfunction that activates PKC persistently and stimulates the continuous synthesis of endogenous ROS, leading to cell damage, including cochlear fibroblasts. 
In this study, there were the differences in the mean values of PKC expression in all groups. The lowest PKC expression was found in the group 1 and the highest PKC expression was found in group 2.

Chronic hyperglycemia can cause various cellular reactions that play a role in the pathomechanism of various complications, caused by cell dysfunction and damage. The cellular reactions caused by chronic hyperglycemia are non-enzymatic glycation, the activation of signal transduction pathway increasing DAG synthesis, the increased ROS synthesis as the waste product of energy catabolism leaing to cell and tissue oxidative stress, and the activation of aldolase reductase. ${ }^{19}$ In diabetes mellitus, the increased ROS production also occurs via a few mechanisms, such as polyol pathway, increased AGEs production, excessive radical superoxide production, and PKC activation. The increased PKC activity may also results in increased ROS production. ${ }^{20}$

The increased DAG synthesis in hyperglycemia via signal transduction pathway, especially that comes from the transformation of glucose into glycerol 3-phosphate, may lead to an increased DAG synthesis de novo. DAG is partially synthesized from Phosphatidyl Choline and Phosphatidyl Inositol of "insulin-sensitive" cell membrane continuously. The perpetual DAG synthesis and the potentiation effect from the free fatty acid in the blood may initiate the PKC activation pathway persistently leading to cellular response, via the modification of various proteins controlling signal transduction and cytokine expression. ${ }^{19,21,22}$

The modification of transcription factor and cell cycle may cause cell dysfunction and damage due to the disturbance in cell proliferation and differentiation as well as the abnormality in apoptosis. Additionally, the modification of transcription factor and post protein translation can also stimulate the synthesis of endogenous ROS resulting in cell damage. ${ }^{19}$

Thereby, in STZ-induced diabetes group, PKC expression was increased due to the continuous activation of PKC pathway.

In this study, it was found that group 3, 4, 5 and 6 (diabetic group with curcumin administration) showed lower mean values of PKC expressions compared to group 2 (diabetic group without curcumin administration). The decreased mean values of PKC expressions in the STZ-induced diabetes 
groups receiving curcumin was due to the activity of curcumin that can eliminate the formation of ROS and thereby inhibiting PKC activation at the cellular level.

A similar study conducted by $\mathrm{Kao}$, et $\mathrm{al}^{23}$ has found the significant inhibition in PKC expressions in patients with hepatocellular carcinoma (Hep $3 B$ cell) treated by curcumin. The decreased expression mechanism of PKC is not fully understood, but many previous in vivo and in vitro studies has shown the strong indication of decreased expression of PKC caused by curcumin act as non competitive and selective inhibitor to fosforilase kinase.

Fosforilase kinase is the key enzyme in glycogen metabolism, if this enzyme were inhibited then autocrine effect as cell growth factor also inhibited which affect the cell proliferation disturbance. other that, curcumin also a potent antioxidant to neutrelized ROS and inhibit the lipid peroxidation. ${ }^{24}$

Similarly, the study carried out by Jancinova et al ${ }^{25}$ has observed that curcumin can inhibit PKC in the neutrophils of Lewis rats suffering from arthritis in vitro or experimentally.

Another study has demonstrated that curcumin can serve as an antioxidant by eliminating phorbol-12, myristate-13 acetate (PMA) to inhibit ROS. This inhibitory pattern shows that curcumin mechanically inhibits PKC and calcium regulation. ${ }^{10}$

The antioxidant activity of curcumin is based on the phenolic group in curcumin through donation of a hydrogen atom. Also, phenolic group plays a key role for the activity of free radicals scavenging. ${ }^{26}$

In this study, the different doses of curcumin $200 \mathrm{mg} / \mathrm{kgbw} /$ day and 400 $\mathrm{mg} / \mathrm{kgbw} /$ day with the duration of 3 and 8 days showed no statistically significant differences $(p>0.05)$ in PKC expressions. Nevertheless, the administration of higher dose of curcumin with longer duration (group 6) demonstrated more decreased PKC expression compared to lower dose of curcumin with shorter duration (group 3).

\section{Conclusion}

According to this study, we conclude that curcumin as an antioxidant that mechanically inhibit the PKC expressions in cochlear fibroblasts of diabetic rats with curcumin administration of either $200 \mathrm{mg} / \mathrm{kgbw} /$ day or 400 
$\mathrm{mg} / \mathrm{kgbw} /$ day for 3 days or 8 days. Curcumin considered as a therapeutic agent that effective in repairing fibroblasts damage in cochlear lateral wall that caused by diabetes melitus, which determined through the expression of PKC. This study can act as a basic science in traditional therapy to manage the hearing loss that caused by diabetes melitus in the future.

\section{Acknowledgements}

This study was supported by DIPA (Direktorat Peneltian Pengabdian kepada Masyarakat Universitas Sumatera Utara) Indonesia. 


\section{References}

1. Malucelli DA, Malucelli FJ, Fonseca VR, Zeigeboim B, Ribas A, Trotta F, et al. Hearing loss prevalence in patients with diabetes mellitus type 1. Brazilian Journal of Otorhinolaryngology. 2012;78(3):105-15.

2. Xipeng L, Ruiyu L, Meng L, Yanzhuo Z, Kaosan G, Liping W. Effect of Diabetes on Hearing and Cochlear Structures. Journal of Otology. 2013;8(2): 82-87

3. Lee HS, Kim KR, Chung WH, Cho YS, Hong SH. Early Sensorineural Hearing Loss in Ob/Ob Mouse, an Animal Model of Type 2 Diabetes. Clinical and Experimental Otorhinolaryngology.2008;1(4):211-16

4. $P$ Noh $H$, King GL.The role of protein kinase $C$ activation in diabetic nephropathy. Kidney International. 2007;72:S49-S53

5. Aronson D. Hyperglycemia and the pathobiology of diabetic complications. $2^{\text {nd }}$ ed.Fisman EZ, Tenenbaum A. Cardiovascular Diabetology: Clinical, Metabolic and Inflammatory Facets. Adv Cardiol. 2008;1-16.

6. Geraldes P., King GL. Activation of Protein Kinase C Isoform and Its Impact on Diabetic Complications. Circulation Research. 2010.106:1319-331

7. Correa, F., Buelna-Chontal, M., Hernandez-Resendiz, S., Garcia-Nino, W.R., Roldan, F.J., Soto, V., Silva-Palacios, A., Amador, A., Pedraza-Chaverri, J., Tapia, E. and Zazueta, C. Curcumin maintains cardiac and mitochondrial function in chronic kidney disease. Free Radical Biology and Medicine.2013;61:119-29

8. Trujillo, J., Chirino, Y.I., Molina, J.E., Anderica, A.C., Tapia E, Pedraza C.J. Renoprotective effect of the antioxidant curcumin : Recent Findings. Redox Biology.2013;1:448-56.

9. Yadav, S.K., Sah, A.K., Jha, R.K., Sah, P. and Shah, D.K. Turmeric (curcumin) remedies gastroprotective action. Pharmacogn Rev.2013;7(13):426.

10.Balasubramanyam, M., Koteswari, A.A., Kumar, R.S., Monickaraj, S.F., Maheswari, J.U, Mohan, V.Curcumin-induced inhibition of cellular reactive oxygen species generation: Novel therapeutic implications. J. Biosci.2003;28(6):15-21.

11. Ragbetli, $C$ and Ceylan, Ebubekir. Effect of Streptozotocin on Biochmical Parameters in Rats. Asian J. Chem.2010;22(3):2376-2378

12. Wongeakin, N., Sridulyakul, P., Jariyapongskul, A., Suksamrarn, A., Patumraj, S. Effect of curcumin and tetrahydrocurcumin on diabetes induced endothelial dysfunction. Afr.J.Biochem.Res.2009;3(5):259-265

13. Tan, K-B and Putti, TC. Cyclooxigenase 2 expression in nasopharyngeal carcinoma: immunohistochemical findings and potential implication. J Clin Pathol.2005;5(8):535-538

14. Austin, D.F., Martin, D.K. and Mcmilan, G.P. Diabetes-Related Change in Hearing. The Laryngoscope.2009;119:1788-796

15. Maia CA, Alberto C. Diabetes Mellitus as etiological factor of hearing loss. Rev Brass Ottorinolaringology.2005;71:208-14

16. Gravel JS, Ruben RJ. Auditory Deprivation and Its Consequences:From Animal Models to Human.In:Van De Water TR, Popper AN, Fay RR, eds.Clinical Aspect of Hearing.New York;Springer;1996:86-92

17. Gonzalez-Salazar A., Molina-Jijon E., Correa F., Zarco-Marquez G., CalderonOliver M., Tapia E., Zazueta C., Pedraza-Chaverri J. Curcumin Protects from 
Cardiac Reperfusion Damage by Attenuation of Oxidant Stress and Mitochondrial Dysfunction. Cardiovasc Toxicol. 2011;11:357-364

18. Van Erk M.J., Teuling E., Staal Y.C.M., Huybers S., van Bladeren P.J., Aarts J.M.M.J.G., van Ommen B. Time- and dose-dependent effects of curcumin on gene expression in human colon cancer cells. Journal of Carcinogenesis. 2004;1-17.

19. Koya, D and King, GL. Protein Kinase C Activation and the Development of Diabetic Complications. American Diabetes Association. Diabetes Journal. 1998;47:859-66

20. Oshiro, Y., Lee, Y.,King, G. Mechanism of diabetic neprhopathy : role of protein kinase-c activation. Advanced studies in medicine.2005;5(1A):10-19

21. Nishizuka, Y. Intracelluler Signaling by Hydrolysis of Phospholipids and Activation of Protein Kinase C. Science of Japan Article.1992; 258:607-13

22. Gutterman D. Vascular Dysfunction in Hyperglycemia : Is Protein Kinase $C$ the Culprit?. Circulation Research. 2002;90:5-7.

23.Kao, H., Wu, JC., Won, SJ., Shin, JW., Liu, HS., Su, CL. Kinase Gene Expression and Subcellular Protein Expression Pattern of Protein Kinase $C$ Isoform in Curcumin-treated Human Hepatocelluler Carcinoma Hep 3B Cells. Plant Foods for Human Nutrition.2011;66:136-142

24. Aggarwal, BB and Reddy, S. Curcumin is a non-competitive and selective inhibitor of phosphorylase kinase. Federation of European Biochemical Societies.1994;94:19-22

25. Jancinova, V., Perecko, T., Nosal, R., Kostalova, D., Bauerova, K., Drabikova, $\mathrm{K}$. Decreased activity of neutrophils in the presence of diferuloylmethane (curcumin) involves protein kinase $\mathrm{C}$ inhibition. European Journal of Pharmacology. 2009;Vol. 612:161-166

26. Menon V.P \& Sudheer A.R. Antioxidant and inflammatory properties of curcumin. Adv Exp Med Biol. 2007;595;105-25 
Table 1. The ANOVA test result in various groups

\begin{tabular}{lrrr}
\hline \multirow{2}{*}{ Grups } & & \multicolumn{2}{c}{ PKC expression } \\
\cline { 3 - 4 } & & Mean \pm SD & P value \\
\hline Group 1 & Group 2 & $-3.2 \pm 0.374$ & $0.000^{*}$ \\
& Group 3 & $-1.0 \pm 0.374$ & 0.200 \\
& Group 4 & $-1.0 \pm 0.374$ & 0.200 \\
& Group 5 & $-0.8 \pm 0.374$ & 0.643 \\
& Group 6 & $-0.6 \pm 0.374$ & 1.000 \\
Group 2 & Group 3 & $2.2 \pm 0.374$ & $0.000^{*}$ \\
& Group 4 & $2.2 \pm 0.374$ & $0.000^{*}$ \\
& Group 5 & $2.4 \pm 0.374$ & $0.000^{*}$ \\
Group 3 & Group 6 & $2.6 \pm 0.374$ & $0.000^{*}$ \\
& Group 4 & $0 \pm 0.374$ & 1.000 \\
Group 4 & $0.2 \pm 0.374$ & 1.000 \\
& Group 6 & $0.4 \pm 0.374$ & 1.000 \\
Group 5 & Group 6 & $0.2 \pm 0.374$ & 1.000 \\
& Group 6 & $0.4 \pm 0.374$ & 1.000 \\
\hline
\end{tabular}

*statistically significant 


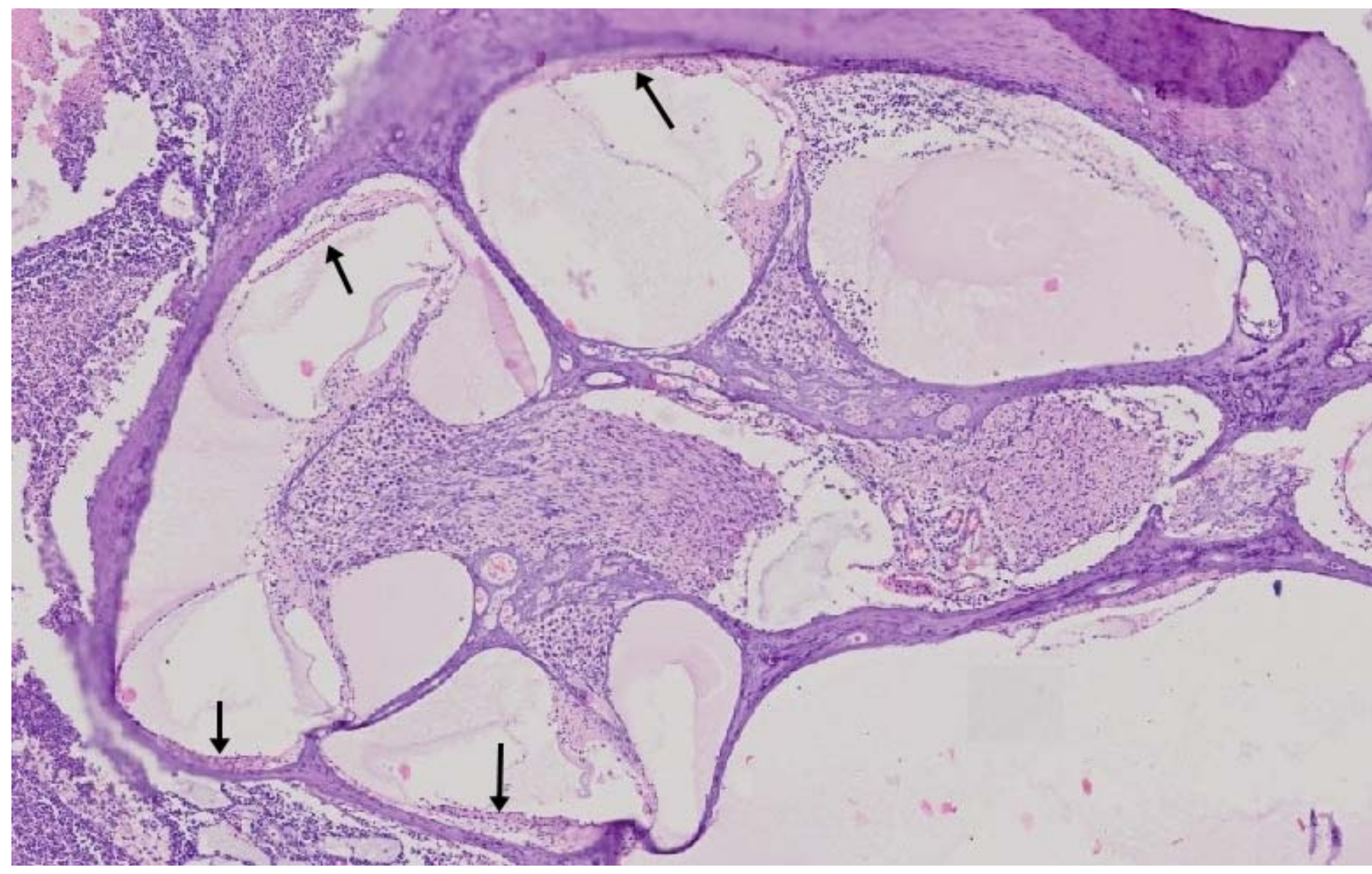




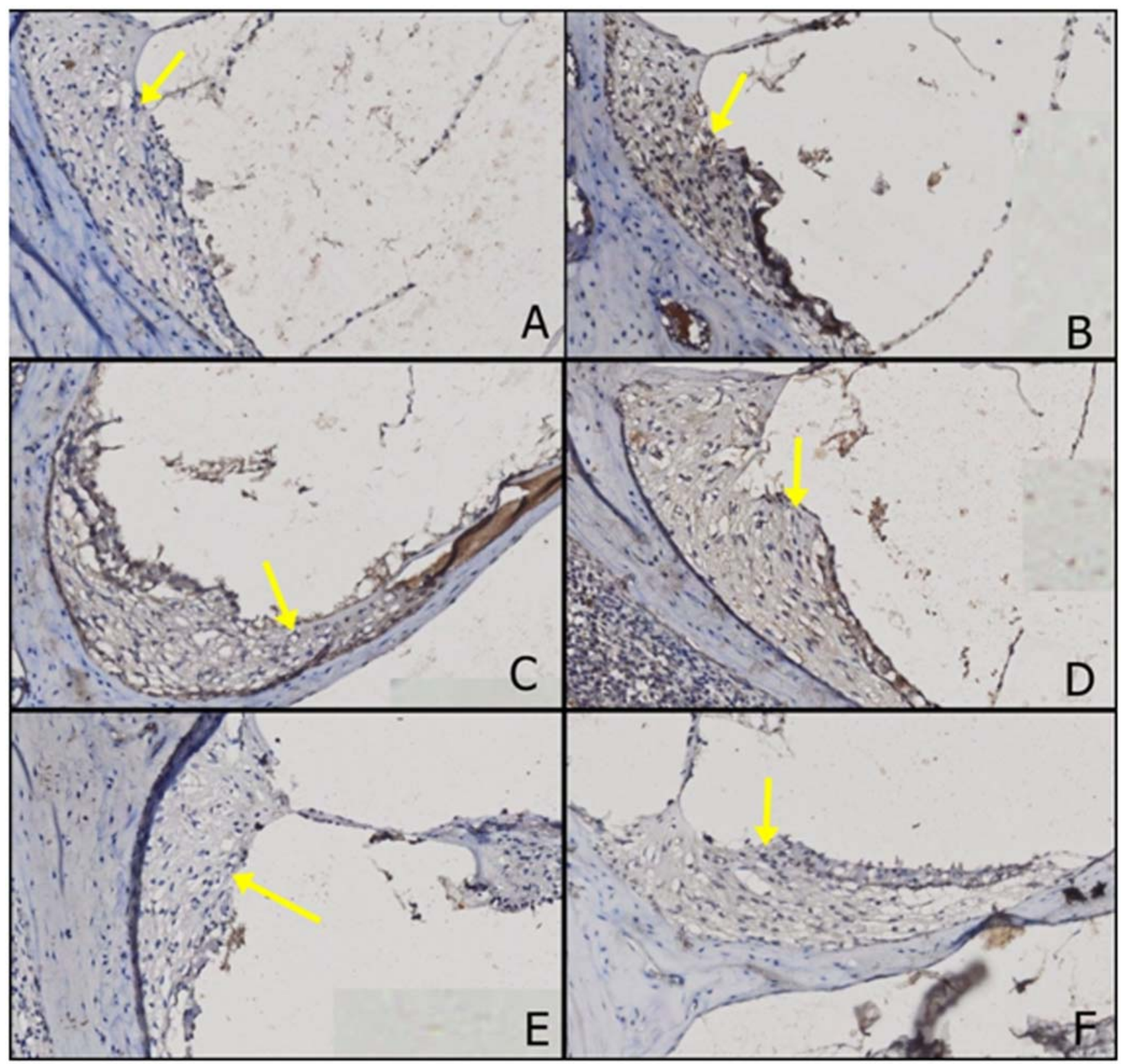




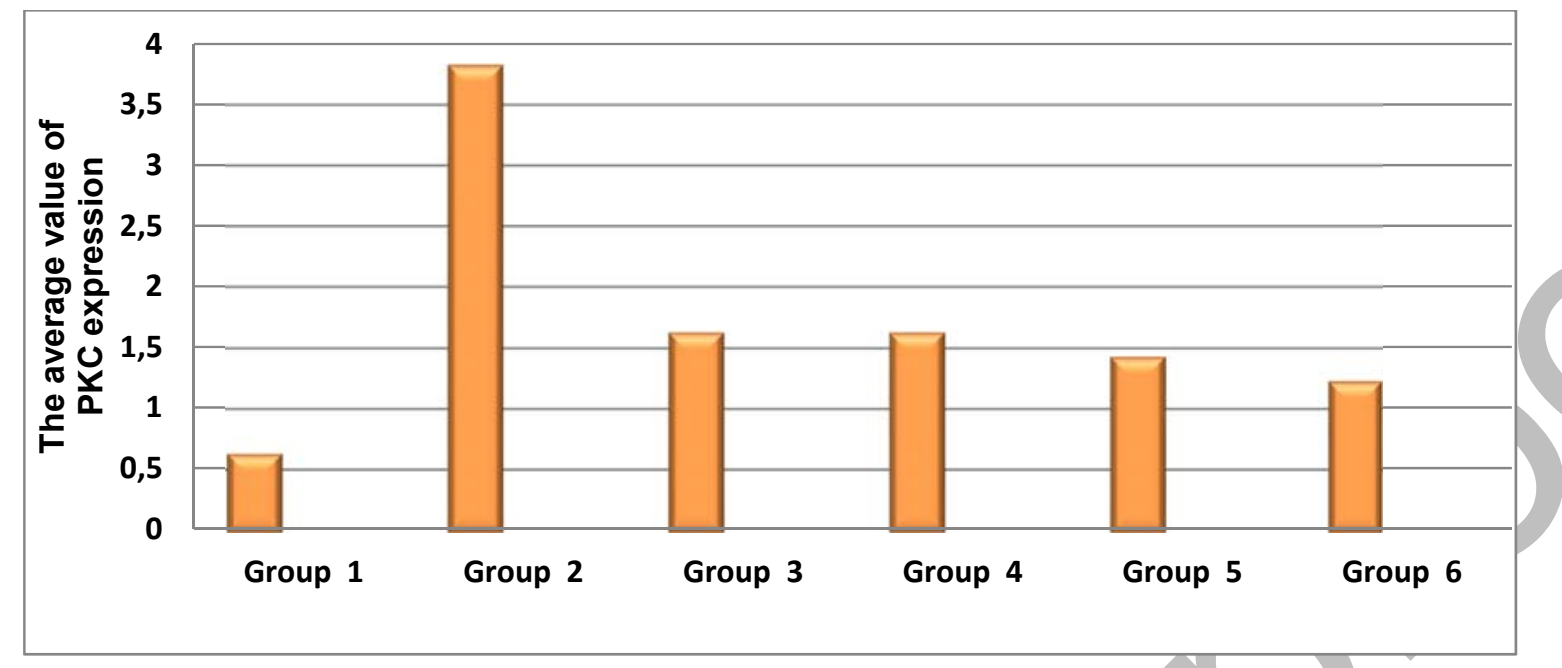

